\title{
Prevalence of Drug-Related Emergency Department Visits at a Teaching Hospital in Malaysia
}

\author{
Abubakar Ibrahim Jatau ${ }^{1}$ Myat Moe Thwe Aung ${ }^{2}$. \\ Tuan Hairulnizam Tuan Kamauzaman ${ }^{3}$ Ab Fatah Ab Rahman ${ }^{1}$
}

Published online: 23 October 2015

(c) The Author(s) 2015. This article is published with open access at Springerlink.com

\begin{abstract}
Background Data on the prevalence of adverse drug event (ADE)-related emergency department (ED) visits in developing countries are limited. Malaysia is located in South-East Asia, and, to our knowledge, no information exists on ADE-related ED visits.

Objective The objective of this study was to determine the prevalence, preventability, severity, and outcome of drug-related ED visits.

Methodology A cross-sectional study was conducted in consenting patients who visited the ED of Hospital Universiti Sains Malaysia over a 6-week period. The ED physician on duty determined whether or not the visit was drug related according to set criteria. Other relevant information was extracted from the patient's medical folder by a clinical pharmacist.

Results Of the 434 consenting patients, 133 (30.6\%; $95 \%$ confidence interval [CI] 26-35\%) visits were determined to be ADE related; $55.5 \%$ were considered preventable, $11.3 \%$ possibly preventable, and $33.1 \%$ not preventable. Severity was classed as mild in $1.5 \%$, moderate in $67.7 \%$, and severe in $30.8 \%$. The most common ADEs reported were drug therapeutic failure $(55.6 \%)$ and adverse drug
\end{abstract}

Abubakar Ibrahim Jatau

pharmjt@gmail.com

1 Faculty of Health Sciences, Universiti Sultan Zainal Abidin, Kampus Gong Badak, Kuala Terengganu, Malaysia

2 Department of Community Medicine, Faculty of Medicine, Universiti Sultan Zainal Abidin, Kampus Kota, Kuala Terengganu, Malaysia

3 Department of Emergency Medicine, School of Medical Sciences, Universiti Sains Malaysia, Kota Bharu, Kelantan, Malaysia reactions $(32.3 \%)$. The most frequently implicated drugs were antidiabetics $(n=31 ; 23.3 \%)$, antihypertensives $(n=28 ; 21.1 \%)$, antibiotics $(n=13 ; 9.8 \%)$, and antiasthmatics $(n=11 ; 8.3 \%)$. A total of 93 patients $(69.9 \%)$ were admitted to the ED for observation, $25(18.8 \%)$ were discharged immediately after consultation, and 15 (11.3\%) were admitted to the ward through the ED.

Conclusion The prevalence of ADE-related ED visits was high; more than one-half of the events were considered preventable and one-third was classed as severe. As such, preventive measures will minimize future occurrences and increase patient safety.

\section{Key Points}

Three in ten patients seeking care at the emergency department of a teaching hospital in Malaysia were for events associated with drug use.

Drug therapeutic failure due to medication nonadherence was the most commonly reported adverse drug event.

\section{Introduction}

An adverse drug event (ADE) is "any untoward medical occurrence in a patient or clinical investigation subject administered a pharmaceutical product and which does not necessarily have to have a causal relationship with this treatment" [1]. ADEs have been identified as a major public health concern and are responsible for a high level of morbidity and mortality worldwide [2]. In the USA, ADEs 
accounted for 17 million emergency department (ED) visits and 8.7 million hospital admissions annually [3]. ADEs occur in all clinical settings and are responsible for $0.77-37.6 \%$ of ED visits [4-6]. They also contributed to an increase in healthcare cost, loss of productivity, increased hospital stay and time away from work, as well as lower patient satisfaction [7-9]. In Canada, ADEs were responsible for a total annual cost of \$Can35.7 million in 2008 [10].

In Malaysia, over 2 million hospital admissions and 19 million outpatient visits were documented in government hospitals in 2014 [11]. Similarly, over 8 million and 33 million prescriptions were dispensed to in-patients and outpatients, respectively [12]. Despite these figures, data on the prevalence of ADE-related hospitalizations in Malaysia are still scarce. Thus, it is necessary to identify the burden of ADEs in an ED to better understand the challenges faced by healthcare professionals in Malaysia.

Many of the previous studies on ADE-related hospitalizations focused on patients in ambulatory care units and those admitted to hospital wards, with relatively few evaluating the number of patients seeking care in the ED [13]. The aim of this study was to determine the prevalence of ADE-related ED visits at a teaching hospital in Malaysia. Our secondary objective was to determine the degree of severity, preventability, and outcome of these visits.

\section{Methods}

\subsection{Settings}

The study was conducted at the ED of Hospital Universiti Sains Malaysia (HUSM), Kelantan, Malaysia. HUSM is a 767-bed tertiary hospital and was considered the largest referral centre in the east coast of Malaysia [14]. The ED receives approximately 65,000 patients per annum.

\subsection{Patients}

All patients coming to the HUSM ED during the period December 2014 to January 2015 were considered for this study. The exclusion criteria were (1) patients referred from another hospital, (2) patients on a scheduled visit to the ED, and (3) patients with medico-legal cases. The remainder of the patients was approached for consent. Only those who consented to participate were interviewed. Recruitment was halted when the required minimum number of patients was reached.

\subsection{Design}

A cross-sectional study was performed over a 6-week period. Patient interviews were conducted between 09:00 am and
05:00 pm, Sunday to Thursday. The ED physician determined whether or not the chief presenting complaints were related to drugs, based on the following criteria [15]: (1) known drug actions as described in drug monographs and/or literature, (2) the temporal relationship between the event and the time of drug use, and (3) the nature of the current underlying disease(s). Information regarding the patient's socio-demographic characteristics, current drug use, current use of any modality of complementary and alternative medicine (CAM), and history of visiting multiple prescribers or pharmacies in the last 14 days were collected. Patient medical and medication history, drug allergy, history of presenting illness, recent hospital admission, drugs dispensed at the ED, and outcome of the visits was also obtained. The categorization of the ADE, preventability, severity, and outcome of the visits were determined based on definitions adopted and modified from previous studies, as described in Sect. 2.4.

\subsection{Definitions}

An ED visit was considered ADE related when the chief presenting complaint was related to drug use [8]. If the patient had other symptoms related to drug use, and the chief presenting complaint was not related to these, the ED visit was considered not ADE related. ADE-related ED visits were classified into the following five categories. (1) Adverse drug reaction (ADR) - $\mathrm{a}$ "response to a drug that is noxious or unintended, and that occurs at doses normally used for the prophylaxis, diagnosis, or therapy of disease" [9]. (2) Drug therapeutic failure (DTF) - an absence of therapeutic response (deterioration of disease state or condition) to a drug that could be linked causally either to a prescribed dose that was too low, medication non-adherence, recent dose reduction and interaction, or inadequate monitoring [16]. The visit was regarded as due to DTF when caused by medication nonadherence where the patient's drug-taking behavior did not correspond with agreed recommendations from the healthcare provider, resulting in a disease or condition not stabilizing or symptoms worsening [17]. (3) Accidental drug overdoseunintentional administration of a drug (set at an amount higher than the normal recommended therapeutic dose, that has the potential to cause harm, e.g., a young child or an adult with impaired mental abilities swallowing medication left within their grasp or an adult mistakenly taking an incorrect drug or dose) [3]. (4) Intentional drug overdose-deliberate administration of a drug at an amount higher than the normal recommended dose, that has the potential to cause harm (e.g., for the purpose of self-harm, suicide attempts, or to achieve euphoric state) [3]. (5) Untreated indication-when the chief presenting complaint is related to a disease or condition that requires a drug therapy and the patient did not seek or receive such therapy (possibly due to mental illness or ignorance of the disease condition) [3]. 
Preventability was evaluated based on three categories [18]: (1) Preventable-the drug-related ED visit was the result of misuse of a drug, inappropriate discontinuation of treatment, non-adherence, or self-medication; (2) Possibly preventable - the visit was due to failure to monitor drug therapy or an error in prescribing, dispensing, or administration; or (3) Not preventable-the ADE occurred during compliance with good drug utilization.

The severity of drug-related ED visits was classified according to the following criteria [19]: (1) Mild-a laboratory abnormality or the symptom did not require drug intervention, (2) Moderate-a laboratory abnormality or symptom that required drug intervention at the ED, (3) Severe-the symptom required hospital admission, was life-threatening, or resulted in permanent disability.

The outcome of the drug-related ED visit was categorized into three groups: (1) discharged immediately after consultation with the ED physician, (2) admitted to the ED-observation ward for a maximum of $72 \mathrm{~h}$, and (3) admitted to a hospital ward through the ED. Drug classification was performed according to MIMS.com Malaysia version 1.3.0 [20].

\subsection{Sample Size Calculation}

The sample size was calculated using a single proportion formula [21], adopting $38.0 \%$ as the expected proportion of population with ADE-related ED visits, as per previous literature [22]; a 0.05 significance (alpha) level at a $95 \%$ confidence interval (CI); and taking into consideration the $20 \%$ of included patients who would leave without seeing a physician. A sample size of 434 was calculated.

\subsection{Statistical Analysis}

Data were analyzed using statistical software (SPSS version 21, SPSS Inc., Chicago, IL, USA). The prevalence of ADE-related ED visits was calculated by dividing the number of patients with ADE-related ED visits by the total sample size. Descriptive analysis of socio-demographic, clinical, and drug-related variables was conducted. Results were presented as frequency (percentage) for categorical variables and mean (standard deviation [SD]) for numerical variables. The Chi squared goodness-of-fit test was used to determine the distribution of cases in a single categorical variable at a 0.05 significance (alpha) level.

\section{Results}

There was a total of 7530 ED visits over the 6-week period; 3573 patients came to the ED between 09:00 am and 05:00 pm Sunday to Thursday. Of the 1162 patients selected for the study, 728 were excluded, for the following reasons: referral from other hospital $(n=714)$; scheduled visit $(n=8)$; declined to participate $(n=4)$; and medicolegal cases $(n=2)$. Therefore, 434 eligible patients were interviewed. The number of ED physician-identified ADErelated ED visits was 133 (30.6\%; $95 \%$ CI 26-35\%). Table 1 illustrates the characteristics of the patients with an ADE-related ED visit. The mean (SD) age of the patients with an ADE-related ED visit was 41.0 (21.58) years. Of the 133 patients, $62 \%$ were female and $96.0 \%$ were of Malay ethnicity. The proportion of patients with formal education was $66.9 \%$, and $70 \%$ of participants were married. A total of 110 patients $(82.7 \%)$ were currently taking medications at the time of the ED visit; $17(12.8 \%)$ claimed use of one or more different modalities of CAM. The most commonly reported chronic diseases among patients with an ADE-related visit were diabetes mellitus (DM) $(n=55 ; 41.4 \%)$; hypertension ( $n=54 ; 40.6 \%)$; and asthma ( $n=13 ; 9.7 \%$ ) (A person could have more than one chronic disease).

Five categories of ADE were reported: (1) DTF $(n=74 ; 55.6 \%)$, (2) ADR $(n=43 ; 32.3 \%)$, (3) accidental drug overdose $(n=7 ; 5.2 \%)$, (4) intentional drug overdose $(n=6 ; 4.5 \%)$, and (5) untreated indication $(n=3 ; 3.2 \%)$. Female patients dominated in most of the ADE categories. The prevalence of DTF, ADR, and accidental overdose was higher among the elderly population ( $\geq 60$ years). Medication non-adherence was found to be the major cause of DTF $(81.1 \%)$. Table 2 demonstrates the prevalence of different categories of ADE among sex and age categories.

Of the 133 ADE-related ED visits, 74 (55.6\%) were considered preventable, with DTF due to medication nonadherence accounting for $85.3 \%$. A total of $41(30.8 \%)$ of ADE-related ED visits were classed as severe, with DTF due to medication non-adherence responsible for $41.5 \%$ of this level of severity. There was no report of permanent disability or death from these visits. Of the subjects, 25 (18.8\%) were discharged immediately after consultation with the ED physician, 93 (69.9\%) were admitted to the ED-observation ward for a maximum of $72 \mathrm{~h}$, and 15 (11.3\%) were admitted to a hospital ward from the ED. Admission to the ED-observation ward was mainly due to hypoglycemia secondary to antidiabetic therapy $(n=10$; $10.8 \%)$, uncontrolled DM $(n=10 ; 10.8 \%)$, and hypertensive urgency $(n=9 ; 9.7 \%)$. Admission to the hospital ward was mostly due to uncontrolled DM ( $n=2 ; 13.3 \%)$.

A total of 45 individual drugs and 18 drug combinations were involved in the 133 ADE-related ED visits. The most frequently implicated drugs were antidiabetics $(n=31$; $23.3 \%)$, antihypertensives $(n=28 ; 21.1 \%)$, antibiotics ( $n=13 ; 9.8 \%)$, anti-asthmatics $(n=11 ; 8.3 \%)$, and diuretics $(n=8 ; 6.0 \%)$. The most frequent single drugs reported were insulin $(n=13 ; 9.8 \%)$, furosemide $(n=7$; 
Table 1 Demographic

characteristics of cases with adverse drug event-related emergency department visit

\begin{tabular}{|c|c|c|c|}
\hline Patient characteristics & Mean age (SD) & Frequency $(\%), n=133$ & $P$ value \\
\hline \multicolumn{4}{|l|}{ Age (years) } \\
\hline$\leq 9$ & & $4(3.0)$ & \multirow[t]{7}{*}{$<0.001$} \\
\hline $10-19$ & & $4(3.0)$ & \\
\hline $20-29$ & & $18(13.5)$ & \\
\hline $30-39$ & & $14(10.5)$ & \\
\hline $40-49$ & & $20(15.0)$ & \\
\hline $50-59$ & & $28(21.1)$ & \\
\hline$\geq 60$ & & $45(33.8)$ & \\
\hline \multicolumn{4}{|l|}{ Sex } \\
\hline Male & $44.45(21.14)$ & $50(38.0)$ & \multirow[t]{2}{*}{0.015} \\
\hline Female & $51.35(16.50)$ & $83(62.0)$ & \\
\hline \multicolumn{4}{|l|}{ Marital status } \\
\hline Single & & $37(28.0)$ & \multirow[t]{3}{*}{0.003} \\
\hline Married & & $93(70.0)$ & \\
\hline Divorced & & $3(2.0)$ & \\
\hline \multicolumn{4}{|l|}{ Ethnicity } \\
\hline Malay & & $128(96.0)$ & \multirow[t]{2}{*}{0.438} \\
\hline Chinese & & $5(4.0)$ & \\
\hline \multicolumn{4}{|l|}{ Education status } \\
\hline None & & $44(33.1)$ & \multirow[t]{2}{*}{0.001} \\
\hline Yes & & $89(66.9)$ & \\
\hline Current drug use & & $110(82.7)$ & 0.522 \\
\hline Male & & $40(36.4)$ & \\
\hline Female & & $70(63.6)$ & \\
\hline \multicolumn{4}{|l|}{ Preventability } \\
\hline Preventable & & $74(55.5)$ & \\
\hline Possibly preventable & & $15(11.3)$ & \\
\hline Not preventable & & $44(33.1)$ & \\
\hline \multicolumn{4}{|l|}{ Severity } \\
\hline Mild & & $2(1.5)$ & \\
\hline Moderate & & $90(67.7)$ & \\
\hline Severe & & $41(30.8)$ & \\
\hline \multicolumn{4}{|l|}{ Outcome of the visit } \\
\hline Discharged immediately & & $25(18.8)$ & \\
\hline Admitted to ED & & $93(69.9)$ & \\
\hline Admitted to the ward & & $15(11.3)$ & \\
\hline
\end{tabular}

$E D$ emergency department, $S D$ standard deviation

${ }^{a}$ Chi square goodness of fit
$2.3 \%)$, salbutamol $(n=6 ; 4.5 \%)$, and gliclazide $(n=5$; $3.8 \%)$. The drug combinations most involved were amoxicillin + clavulanic acid $(n=4 ; 3.0 \%)$ and rifampicin + isoniazid $(n=3 ; 2.3 \%)$.

The most common complaints among patients with ADErelated ED visits were fatigue, irritability, sweating, unconsciousness, hypertension, skin reactions, upper gastrointestinal bleeding, palpitations, giddiness, shortness of breath, tarry stools, abnormal behavior, chest pain, convulsions, lethargy, edema, and Stevens-Johnson Syndrome (SJS).

\section{Discussion}

To our knowledge, this is the first study to determine the prevalence of ADE-related ED visits at a teaching hospital in Malaysia. A prevalence of $30.6 \%$ (95 \% CI 26-35) for ADE-related ED visits was determined within the 6-week period. More than one-half of the ADEs were determined to have been preventable, and almost one-third had a severe outcome. The prevalence rate found in the current study is consistent with results of previous studies 
Table 2 Categories of adverse drug events among sex and age categories

\begin{tabular}{|c|c|c|c|c|c|c|}
\hline & \multicolumn{5}{|c|}{ Categories of adverse drug event, $n(\%)^{\mathrm{a}}$} & \multirow[t]{2}{*}{$P$ value $^{\mathrm{b}}$} \\
\hline & DTF & ADR & Accidental drug overdose & Intentional drug overdose & Untreated indication & \\
\hline \multicolumn{7}{|l|}{ Sex } \\
\hline Male & $30(40.5)$ & $12(27.9)$ & $4(57.1)$ & $4(66.7)$ & $0(0.0)$ & 0.160 \\
\hline Female & $44(59.5)$ & $31(72.1)$ & $3(42.1)$ & $2(33.3)$ & $3(100)$ & \\
\hline \multicolumn{7}{|c|}{ Age category (years) } \\
\hline$\leq 9$ & $3(1.6)$ & $0(0.0)$ & $1(14.3)$ & $0(0.0)$ & $0(0.0)$ & $<0.001$ \\
\hline $10-19$ & $1(0.0)$ & $2(4.7)$ & $1(14.3)$ & $0(0.0)$ & $1(33.3)$ & \\
\hline $20-29$ & $6(9.5)$ & $8(18.6)$ & $0(0.0)$ & $3(50.0)$ & $0(0.0)$ & \\
\hline $30-39$ & $8(11.1)$ & $5(11.6)$ & $0(0.0)$ & $1(16.7)$ & $2(66.7)$ & \\
\hline $40-49$ & $7(9.5)$ & 8 (18.6) & $1(14.3)$ & $2(33.3)$ & $0(0.0)$ & \\
\hline $50-59$ & $22(31.7)$ & $5(11.6)$ & $1(14.3)$ & $0(0.0)$ & $0(0.0)$ & \\
\hline$\geq 60$ & 27 (36.5) & $15(34.9)$ & $3(42.9)$ & $0(0.0)$ & $0(0.0)$ & \\
\hline Prevalence $^{c}$ & 17.0 & 9.9 & 1.6 & 1.4 & 0.7 & \\
\hline
\end{tabular}

$A D R$ adverse drug reaction, $D T F$ drug therapeutic failure

${ }^{a}$ Frequency is calculated as the number of cases in 133 patients with adverse drug event-related emergency department visits

${ }^{\mathrm{b}}$ Chi squared goodness of fit

${ }^{c}$ Prevalence is calculated as the percentage of cases with adverse drug events in the sample size (434)

conducted in Spain and the USA using a similar study design and population (28.1-33.2 \%) [23-26]. In contrast, the prevalence rate was higher than in other studies performed in England, Finland, Canada, and Taiwan, which were in the range of $0.77-4.0 \%$ [24, 27-30]. In the current study, the rate of ADE-related admissions to the ward through the ED was $11.3 \%$, which is similar to rates found in a study conducted in Malaysia (12.7\%) [31]. The high prevalence rate found in this study may be due to a broader definition of ADE, eligibility criteria, and study population used. This was adopted to ensure a comprehensive knowledge of ADE-related hospitalization. Moreover, the high proportion of patients with DTF may also be responsible for the high prevalence rate.

In the current study, the proportion of female patients found to be associated with ADE-related ED visits and currently receiving medications was higher than that of male patients. This was in agreement with previous studies [27, 32, 33]. The female sex has been identified as a risk factor associated with ADE-related ED visits [23, 25, 34, 35]. This is possibly due to the increased bioavailability of drugs, greater sensitivity of female target organs to drugs, and polypharmacy due to gender-specific treatments [36]. ADE-related complaints at the ED in the current study were higher among the elderly. This was consistent with findings of previous studies [4, 7, 24, 37]. This could possibly be because the body's ability to handle drugs diminishes with age, leading to changes in drug pharmacokinetics, altered organ responses, and homeostatic counter-regulation to drug effects [38]. More patients without formal education had ADE-related ED visits than patients with higher education. Similar studies have shown that patients with a higher level of education have a better perception of the risks of ADEs [39]. A higher level of education brings a greater conscious awareness of the risks associated with drug use. Many previous studies on prevalence of ADEs did not evaluate marital status [13]. However, our study reveals a significant difference in ADE occurrence within married, divorced, and single patients, with a married population having a higher percentage of patients with ADE-related ED visits. Similarly, Chrischilles et al. [40, 41] and Hema et al. [40, 41] also found that a higher proportion of patients with ADE were married. An explanation for this within the current study may be that over $40 \%$ of the patients with ADEs were elderly and more than one-half were females, who were earlier found to have a higher incidence of ADE-related hospitalization.

The ADE category with the highest prevalence rate in the current study was DTF, which accounted for more than one-half of ADE-related ED visits. This is consistent with a similar study conducted in a hospital ward in Malaysia [22]. In the current study, medication non-adherence was the major cause of DTF-related ED visits. The prevalence rate of DTF due to medication non-adherence reported was higher than that found in previous studies [8, 15, 42-44]. This variation may be due to more patients with chronic diseases visiting our ED with ADE-related complaints. However, patients with underlying chronic illness were found to have a higher chance of medication non-adherence [43]. Another reason for the higher prevalence rate of DTF due to medication non-adherence may be associated 
with the busy and overcrowded nature of some public hospitals in Malaysia, which may not allow adequate patient counseling, especially regarding medication adherence $[45,46]$. Medication non-adherence has become a silent burden of healthcare [39, 44, 47]; thus, many intervention measures have been made to improve adherence to increase patient safety. Such interventions include patient education via verbal and written instructions, illustrations, and audiovisuals by healthcare providers, and reminders such as medication calendars, medication schedule alerts, stickers, box alarms, and pill timers. In Malaysia, efforts have been made to improve medication adherence, including the use of short message alerts, called MySMS $^{\circledR}$, in some hospitals [48] and the establishment of Medication Therapy Adherence Clinic (MTAC) services operated by pharmacists in some public hospitals. These services have resulted in significant improvements in medication adherence [49]. Studies have shown that pharmacist interventions have played a major role in improving medication adherence, especially among patients with chronic illness. The pharmacist is an expert on drugs and has the skills and expertise to improve medication adherence and potentially minimize the prevalence of DTF-related ED visits [50, 51]. More intervention measures are needed to improve medication adherence.

In the current study, ADRs account for one-third of the ADE-related ED visits. This rate is consistent with similar studies conducted in India [52] and in hospital wards in Malaysia and Germany [33, 38]. Hypoglycemia was the most common complaint associated with ADRs, mainly related to antidiabetic therapy (gliclazide and insulin). The high rate of ADRs in the current study may be explained by the poor ADR monitoring and reporting system in Malaysia. Despite the establishment of the Malaysian Adverse Drug Reaction Advisory Committee (MADRAC) in 1987 to receive and monitor ADR reporting, the response is still very low compared with other countries [53]. Reports have identified some of the factors associated with under-reporting of ADRs in Malaysia, including (1) lack of awareness on the importance of and the need for ADR monitoring and reporting, (2) uncertainty about whether or not the event was an ADR, (3) opinion that the reaction was too trivial or well known to report, (4) lack of knowledge on how to report, and (5) inadequate time for reporting [54]. If ADRs are not reported, then, predictably, the extent of the occurrence, the people at risk, and the drugs involved will not be well known. As such, preventive interventions will be hampered, leading to increasing numbers of ADRs. Another reason for the high ADR prevalence rate in our study may be related to the current treatment guidelines for DM and the poor glycemic control associated with oral antidiabetic drugs. In Malaysia, prevalence of DM is high, at $20 \%$ [55, 56], and the majority of patients have experienced sub-optimal glycemic control with oral hypoglycemic drugs. Thus, early insulin therapy has been included in the current treatment guidelines for DM, and this has led to increased levels of insulin use $[57,58]$. However, this may be responsible for the high prevalence of ADRs related to insulin-induced hypoglycemia in the current study. Healthcare providers should therefore discuss and monitor insulin therapy with their patient, with regards to possible ADRs and how to manage hypoglycemia associated with the therapy.

More than one-half of the ADEs identified were preventable, with over $80 \%$ contributed by DTF and $50 \%$ by females. This is similar to results found in Saudi Arabia and Canada [12, 19, 59]. These findings signal the possibility of preventing more ADEs by improving medication adherence and minimizing other preventable ADEs identified. Healthcare professionals and policy makers should therefore focus their attention, efforts, and resources to the identified preventable ADEs to improve patient safety [60].

In the current study, almost one-third and two-thirds of the ADE-related ED visits were severe and moderately severe, respectively; this is similar to findings in other studies [26, 61]. A high proportion of females experienced severe outcomes from ADEs due to ADRs and DTF, which is also consistent with previous studies [42, 62]. These findings have shown the healthcare challenges posed by DTF and ADRs, and hence, the urgent need for interventions to prevent further occurrences. There were no reports of death or permanent disability within the current study, although two patients presented with SJS, involving oral cloxacillin and a topical skincare cream containing collagen $\left(\right.$ Dnarz $\left.{ }^{\circledR}\right)$. This is similar to a retrospective cohort study among patients of Asian descent, which found cloxacillin to be among the drugs causing SJS [63]. The pathogenesis of SJS was believed to be due to genetic susceptibility, therefore, more pharmacogenomics studies are needed to determine the drugs and groups of people at high risk of SJS [63].

In the current study, more than two-thirds of the cases were admitted to the ED-observation ward and experienced more severe ADEs. Most presented with hypoglycemic and hypertensive symptoms associated with anti-diabetic and antihypertensive use. Therefore, a need exists for a clinical pharmacist in the ED, for adequate detection, reporting, and preventing of ADEs. Pharmacists, as drug experts, specialize in recognizing ADEs in all clinical settings. Consequently, most physicians lack adequate knowledge and expertise to detect and report ADEs, and it has been reported that over $40 \%$ of ADEs presented at EDs were misdiagnosed by ED physicians [64]. 
The classes of drug most frequently implicated were anti-diabetics, cardiovascular system agents, central nervous system agents, antibiotics, anti-asthmatics, and diuretics, similar to findings from other studies $[15,61,65-$ 68]. This may be associated with the higher number of patients with chronic illness reported in the study. Insulin, furosemide, salbutamol, gliclazide, and amlodipine were the most commonly reported drugs. Similar studies have shown that these drugs have been associated with an increased likelihood of ADE-related ED visits [50, 69, 70]. Amphetamine was commonly associated with intentional drug overdose among male patients. This indicates a need for close monitoring and patient counseling when prescribing and dispensing such drugs given their potential to cause ADEs leading to ED visits.

Limitations of this study include that it was limited to one hospital, and the findings may not be generalized to a larger population in Malaysia. In addition, the study period, sample, and lack of internal validation of ADEs could further affect the results reported.

\section{Conclusion}

The prevalence of ADE-related ED visits in Malaysia is high. More than one-half of these visits were preventable and due to DTF. Medication non-adherence was the major cause of DTF and was responsible for the high percentage of severe ADEs admitted to the ED-observation ward. This indicates the need for an effective intervention strategy, such as patient education on drug utilization, engaging the services of a clinical pharmacist at the ED, and other measures targeted at preventable ADEs to improve patient safety.

Acknowledgments The authors would like to thank the physicians on duty at the HUSM ED during the period of study. The assistance of the nurses and other paramedics is gratefully acknowledged.

\section{Compliance with Ethical Standards}

The study was approved by the ethics committee of Universiti Sultan Zainal Abidin (UniSZA) and Universiti Sains Malaysia (USM) and has been performed in accordance with the ethical standards of the Declaration of Helsinki. Informed consent was obtained from all individual participants included in the study.

Conflict of interest Pharm Abubakar Ibrahim Jatau, Dr Myat Moe Thwe Aung, Dr Tuan Hairulnizam Tuan Kamauzan and Prof Ab Fatah Ab Rahman all declare that they have no conflict of interest.

Funding No specific funding was received for this research.

Open Access This article is distributed under the terms of the Creative Commons Attribution-NonCommercial 4.0 International License (http://creativecommons.org/licenses/by-nc/4.0/), which permits any noncommercial use, distribution, and reproduction in any medium, provided you give appropriate credit to the original author(s) and the source, provide a link to the Creative Commons license, and indicate if changes were made.

\section{References}

1. International Conference on Harmonization-Efficacy. http:// www.fda.gov/downloads/Drugs/GuidanceComplianceRegulatory Information/Guidances/UCM073087.pdf.

2. Kane-Gill SL, Kirisci L, Verrico MM, Rothschild JM. Analysis of risk factors for adverse drug events in critically ill patients. Crit Care Med. 2012;40(3):823.

3. Hepler CD, Strand LM. Opportunities and responsibilities in pharmaceutical care. Am J Hosp Pharm. 1990;47(3):533-43.

4. Field TS, Gurwitz JH, Harrold LR, Rothschild J, DeBellis KR, Seger AC, et al. Risk factors for adverse drug events among older adults in the ambulatory setting. $\mathrm{J}$ Am Geriatr Soc. 2004;52(8):1349-54.

5. Chen YC, Fan JS, Hsu TF, Chen MH, Huang HH, Cheng KW, et al. Detection of patients presenting with adverse drug events in the emergency department. Intern Med J. 2012;42(6):651-7.

6. Castro I, Guardiola JM, Tuneu L, Sala ML, Faus MJ, Mangues MA. Drug-related visits to the emergency department in a Spanish university hospital. Int J Clin Pharm. 2013;35(5): 727-35.

7. Wu C. Bell, Chaim M, Wodchis, Walter P. Incidence and economic burden of adverse drug reactions among elderly patients in Ontario Emergency Departments. Drug Saf. 2012;35(9):769-81.

8. Zed PJ, Abu-Laban RB, Balen RM, Loewen PS, Hohl CM, Brubacher JR, et al. Incidence, severity and preventability of medication-related visits to the emergency department: a prospective study. CMAJ. 2008;178(12):1563-9.

9. World Health Organisation. International Drug Monitoring: the role of a hospital. Technical Series No. 425. 1969; 426: 5-24.

10. Chen $\mathrm{Wu} \mathrm{CMB}$ WPW. Incidence and economic burden of adverse drug reactions among elderly patients in Ontario Emergency Departments a retrospective study. Drug Saf. 2012;9:769-81.

11. Malaysia MoH. Health facts 2014. In: Center PDHI, editor. Putrajaya: Ministry of health Malaysia; 2014. p. 11-2.

12. Malaysia $\mathrm{MoH}$. Guidelines for medication error reporting. In: Division PS, editor. 1 ed. Selangor Ministry of Health Malaysia; 2009. p. 30.

13. Zed PJ. Drug-related visits to the emergency department. J Pharm Prac. 2005;18(5):329-35.

14. Shah C, Ismail IM, Mohsin S. Ambulance response time and emergency medical dispatcher program: a study in Kelantan, Malaysia. 2008.

15. Queneau P, Trombert B, Carpentier F, Trinh-Duc A, Bannwarth B, Bouget J, editors. Adverse drug effects: a prospective study by Apnet performed in seven emergency care units in France: propositions for preventive measures. Ann Pharm Fr. 2005.

16. Hallas J, Harvald B, Worm J, Beck-Nielsen J, Gram L, Grodum E, et al. Drug related hospital admissions. Eur J Clin Pharmacol. 1993;45(3):199-203.

17. World Health Organisation. Report on Medication Adherence. World Health Organisation. Geneva. 2003; 4. http://www.who. int/chp/knowledge/publications/adherence_full_report.pdf.

18. Nelson KM, Talbert RL. Drug-related hospital admissions. Pharmacother. 1996;16(4):701-7.

19. Singh H, Kumar BN, Sinha T, Dulhani N. The incidence and nature of drug-related hospital admission: a 6-month observational study in a tertiary health care hospital. J Pharmacol Pharmacother. 2011;2(1):17. 
20. Drug information system [database on the Internet]. MIMS 2015. https://www.mims.com/home/index?aspxerrorpath=/Malaysia. Accessed 06 May 2015.

21. Naing L, Than W, Rusli B. Practical issues in calculating the sample size for prevalence studies. 2006.

22. Karuppannan M, Nee TK, Ali SM, Thong WK, Boardman H. The prevalence of adverse drug event-related admissions at a local hospital in Malaysia. Arch Pharm Pract. 2013;4(4):160.

23. Capuano A, Irpino A, Gallo M, Ferrante L, Illiano M, Rinaldi B, et al. Regional surveillance of emergency-department visits for outpatient adverse drug events. Eur J Clin Pharmacol. 2009;65(7):721-8.

24. Baena MI, Faus MJ, Fajardo PC, Luque FM, Sierra F, MartinezOlmos J, et al. Medicine-related problems resulting in emergency department visits. Eur J Clin Pharmacol. 2006;62(5):387-93.

25. Ramos Linares S, DíazRuiz P, Mesa Fumero J, et al. Incidence rate of adverse drug effects in a hospital emergency unit and its associated factors. J Farma. 2010;34(6):271-8.

26. Tafreshi MJ, Melby MJ, Kaback KR, Nord TC. Medication-related visits to the emergency department: a prospective study. Ann Pharmacother. 1999;33(12):1252-7.

27. Sikdar KC, Alaghehbandan R, MacDonald D, Barrett B, Collins $\mathrm{KD}$, Donnan J, et al. Adverse drug events in adult patients leading to emergency department visits. Ann Pharmacother. 2010;44(4):641-9.

28. Juntti-Patinen L, Kuitunen T, Pere P, Neuvonen PJ. Drug-related visits to a District Hospital Emergency Room. Basic Clin Pharmacol Toxicol. 2006;98(2):212-7.

29. Trifirò G, Calogero G, Ippolito FM, Cosentino M, Giuliani R, Conforti A, et al. Adverse drug events in emergency department population: a prospective Italian study. Pharmacoepidemiol Drug Saf. 2005;14(5):333-40.

30. Bednall R, McRobbie D, Hicks A. Identification of medicationrelated attendances at an A \& E department. J Clin Pharm Ther. 2003;28(1):41-5.

31. Farooqui M, Noorizan A, Hassan Y, Azhar S, Ghazalli R. Drug related problems as a cause of admission to the medical wards of hospital Pulau Pinang. Malays J Pharm Sci. 2005;3(2):65-6.

32. Schneitman-McIntire O, Farnen TA, Gordon N, Chan J, Toy WA. Medication misadventures resulting in emergency department visits at and HMO medical center. Am J Health Syst Pharm. 1996;53(12):1416-22.

33. Olshaker JS, Barish RA, Naradzay JF, Jerrard DA, Safir E, Campbell L. Prescription noncompliance: contribution to emergency department visits and cost. Eur J Emerg Med. 1999;17(5):909-12.

34. De Paepe P, Petrovic M, Outtier L, Van Maele G, Buylaert W. Drug interactions and adverse drug reactions in the older patients admitted to the emergency department. Acta Clin Belg. 2013;68(1):15-21.

35. Zopf Y, Rabe C, Neubert A, Hahn EG, Dormann H. Risk factors associated with adverse drug reactions following hospital admission. Drug Saf. 2008;31(9):789-98.

36. Drici M-D, Clément N. Is gender a risk factor for adverse drug reactions? Drug Saf. 2001;24(8):575-85.

37. Sarkar U, López A, Maselli JH, Gonzales R. Adverse drug events in US adult ambulatory medical care. Health Serv Res. 2011;46(5):1517-33.

38. Cusack B, Nielson C, Vestal R. Geriatric clinical pharmacology and therapeutics. Avery's Drug treatment 4th ed Auckland, New Zealand: Adis International. 1997: 173-223.

39. Salvo F, Miroddi M, Alibrandi A, Calapai F, Cafeo V, Mancari F, et al. Attitudes and opinion about adverse drug events of women living in a city of south Italy. Pharmacol. 2013;91(3-4):173-7.

40. Chrischilles E, Rubenstein L, Van Gilder R, Voelker M, Wright $\mathrm{K}$, Wallace R. Risk factors for adverse drug events in older adults with mobility limitations in the community setting. J Am Soc Geriatr Dent. 2007;55(1):29-34.

41. Hema NG, Bhuvana KB, Virupaksha HM. Critical assessment of adverse drug reactions to antitubercular drugs in a government teaching hospital. Intern J Basic Med Sci. 2013;5(5):60-7.

42. Al-Arifi M, Abu-Hashem H, Al-Meziny M, Said R, Aljadhey H. Emergency department visits and admissions due to drug related problems at Riyadh military hospital (RMH), Saudi Arabia. Saudi Pharm J. 2014;22(1):17-25.

43. Malhotra S, Karan R, Pandhi P, Jain S. Drug related medical emergencies in the elderly: role of adverse drug reactions and non-compliance. Postgrad Med J. 2001;77(913):703-7.

44. Heaton PC, Tundia NL, Luder HR. US emergency departments visits resulting from poor medication adherence: 2005-07. JAPhA. 2012;53(5):513-9.

45. Ir MD, Johari Dato MohdGhazali R, Hazilah Abd Manaf N, Hassan Asaari Abdullah A, Abu Bakar A, Salikin F, et al. Hospital waiting time: the forgotten premise of healthcare service delivery? Int J Health Care Qual Assur. 2011;24(7):506-22.

46. Hazilah Abd Manaf N, Siew Nooi P. Patient satisfaction as an indicator of service quality in Malaysian public hospitals. Asian J Qual. 2009;10(1):77-87.

47. Lewis A. Non-compliance: a $\$ 100$ billion problem. Remington Report. 1997;5(4):14-5.

48. Peterson AMTLFR. Meta-analysis of trials of interventions to improve medication adherence. Am J Health Syst Pharm. 2003;60(7):657-65.

49. Phei Ching L, Kelvin L. Evaluation of a pharmacist-managed diabetes medication therapy adherence clinic. Pharm Pract. 2010;8(4):250-4.

50. Lee JK, Grace KA, Taylor AJ. Effect of a pharmacy care program on medication adherence and persistence, blood pressure, and low-density lipoprotein cholesterol: a randomized controlled trial. JAMA. 2006;296(21):2563-71.

51. Brennan TA, Dollear TJ, Hu M, Matlin OS, Shrank WH, Choudhry NK, et al. An integrated pharmacy-based program improved medication prescription and adherence rates in diabetes patients. Health Aff. 2012;31(1):120-9.

52. Winterstein AG, Sauer BC, Hepler CD, Poole C. Preventable drug-related hospital admissions. Ann Pharmacother. 2002;36(7-8):1238-48.

53. Mayasia MoH. Guidelines for medication error reporting.. In: Division PS, editor. Selangor: Pharmaceutical Services Division; 2009. p. 30.

54. Aziz Z, Siang TC, Badarudin NS. Reporting of adverse drug reactions: predictors of under-reporting in Malaysia. Pharmacoepidemiol Drug Saf. 2007;16(2):223-8.

55. IDF. Diabetes in Malaysia-2014. In: Malaysia. Brussels. 2014. http://www.idf.org/membership/wp/malaysia. Accessed 9 may 2015.

56. Amal N, Paramesarvathy R, Tee G, Gurpreet K, Karuthan C. Prevalence of Chronic Illness and Health Seeking Behaviour in Malaysian Population: results from the Third National Health Morbidity Survey (NHMS III) 2006. Med J Malaysia. 2011;66(1):36-41.

57. WMW B. National Launching of the "Clinical Practice Guidelines: Management of Type 2 Diabetes Mellitus. In: Society MEM, editor. 4 ed. Kuala Lumpur: Malaysian Endocrine and Metabolic Society; 2009.

58. MEaM. Practical guide to insulin therapy in Type 2 Diabetes Mellitus. In: Society MEaM, editor. Kuala Lumpur: Malaysian Endocrine and Metabolic Society; 2011.

59. Rashed AN, Neubert A, Alhamdan H, Tomlin S, Alazmi A, AlShaikh A, et al. Drug-related problems found in children attending an emergency department in Saudi Arabia and in the United Kingdom. Inter J Clin Pharm. 2013;35(3):327-31. 
60. Kohn LT, Corrigan JM, Donaldson MS. To err is human: building a Safer Health System. Washington: National Academies Press; 2000.

61. Smith KM, McAdams JW, Frenia ML, Todd MW. Drug-related problems in emergency department patients. AJHP. 1997;54(3):295.

62. Dennehy CE, Kishi DT, Louie C. Drug-related illness in emergency department patients. Am J Health Syst Pharm. 1996;53(12):1422-6.

63. Koh MJ, Tay YK. Stevens-Johnson syndrome and toxic epidermal necrolysis in Asian children. J Am Acad Dermatol. 2010;62(1):54-60.

64. Hohl CM, Zed PJ, Brubacher JR, Abu-Laban RB, Loewen PS, Purssell RA. Do emergency physicians attribute drug-related emergency department visits to medication-related problems? Ann Emerg Med. 2010;55(6):493-502.

65. Stoukides C, D'agostino P, Kaufman M. Adverse drug reaction surveillance in an emergency room. AJHP. 1993;50(4):712-4.
66. Prince B, Goetz C, Rihn T, Olsky M. Drug-related emergency department visits and hospital admissions. Am J Health Syst Pharm. 1992;49(7):1696-700.

67. Sekhar MS, Mary CA, Anju P, Hamsa NA. Study on drug related hospital admissions in a tertiary care hospital in South India. Saudi Pharm J. 2011;19(4):273-8.

68. Alghamdy MS, Randhawa MA, Al-Wahhas MH, Al-Jumaan MA. Admissions for drug-related problems at the Emergency Department of a University Hospital in the Kingdom of Saudi Arabia. J Family Community Med. 2015;22(1):44.

69. Jayarama N, Shiju K, Prabahakar K. Adverse drug reactions in adults leading to emergency department visits. Int J Pharm Pharm Sci. 2012;4:642-6.

70. Olivier P, Bertrand L, Tubery M, Lauque D, Montastruc J-L, Lapeyre-Mestre M. Hospitalizations because of adverse drug reactions in elderly patients admitted through the emergency department. Drugs Aging. 2009;26(6):475-82. 